\title{
Prevalence and Determinant Factors of Osteoarthritis of the Knee Joint among Elderly in Arar, KSA \\ Khalid Waleed AlKuwaity ${ }^{1}$, Tasneem Noor Mohammad ${ }^{2}$, Malik Azhar Hussain ${ }^{3}$, Annas Jamal Alkhanani ${ }^{4}$, Abdulla Mohamed Bakr Ali ${ }^{5}$ \\ ${ }^{1}$ College of Medicine, King Faisal University, Al Ahsa, ${ }^{2}$ Microbiology department, Faculty of Applied Medical sciences, Northern Border University, Arar, ${ }^{3}$ Surgery department, College of Medicine, Northern Border University, Arar, Saudi Arabia, ${ }^{4}$ College of Medicine, 6 October University, Cairo, ${ }^{5}$ Faculty of Medicine, Sohag University, Egypt.
}

\begin{abstract}
Background: Osteoarthritis of the knee, the disease of knee joint dysfunction and pain caused by joint degeneration, it is the commonest joint disease. In most cases of joint degeneration there is no clear identifiable cause, but increasing age, excessive joint loading, and joint abnormalities and trauma increase the risk of OA. It has significant effects on human health and quality of life (QoL). Objective: This study was carried out aimed to determine the prevalence and determinant factors of osteoarthritis of the knee among elderly population in Arar, KSA. Methods: The present cross sectional community based study was conducted in Arar city, the capital of Northern Borders Governorate on 238 elderly people of age 60 years and more. Data was collected through personal interviews with the sampled population and filling a predesigned questionnaire. It included questions regarding the already previously diagnosed osteoarthritis of the knee joint and its determinants. Results: the mean age ( \pm SD) was $70.4( \pm 9.3)$ years, male to female ratio was 48.3 to 51.7. The overall prevalence rate of osteoarthritis of the knee joint was $24.5 \%$.Osteoarthritis was almost equal in females and males (26.8\% and $26.1 \%$, respectively), it was insignificantly associated with increasing age, female sex, hypertension and diabetes ( $\mathrm{P}>0.05)$, while significantly associated with the BMI. Conclusion: Osteoarthritis of the knee joint is common among elderly population in Arar, KSA. It was almost equal in females and males.
\end{abstract}

Keywords: Osteoarthritis, knee joint, elderly, Arar, KSA, determinants, prevalence.

\section{INTRODUCTION}

Musculoskeletal diseases are major public health problems, they cause more functional limitations in the adult and geriatric population in most welfare states than any other group of disorders. They are a major cause of years lived with disability in all continents and economies, but figures for the prevalence of most musculoskeletal disease are scarce ${ }^{1}$.

Osteoarthritis (OA) is the most common arthritic condition worldwide. It has considerable social and economic impact with an estimated annual cost in medical care and lost work running into billions of dollars ${ }^{2}$. It is characterized by altered joint anatomy, especially the loss of articular cartilage. Pathologically OA may be defined as a condition of synovial joints characterized by focal loss of articular cartilage and simultaneous proliferation of new bone (osteophytes) with the remodeling of joint contour ${ }^{3}$.

The precise mechanism of cartilage degradation in osteoarthritis is still unclear, but a complex interplay of genetic, environmental, metabolic and biochemical factors is proposed ${ }^{4}$.

The prevalence varies in different regions of the world with prevalence rates ranging from 3.8-70\% depending on the methodology of studies, whether clinical, radiographic, patient selfreporting or physician diagnosis ${ }^{5}$. As the incidence and prevalence of osteoarthritis rise with increasing age, extended life expectancy will result in a greater number of people with the condition. In the
United Kingdom (UK) $20 \%$ to $30 \%$ of elders over 60 years have symptomatic osteoarthritis ${ }^{6}$.

In the Middle East, more than one million people suffer from OA in Iraq, Yemen, Saudi Arabia, and Syria ${ }^{7}$.

Approximately $85 \%$ of individuals over the age of 75 years of age experience some symptoms of osteoarthritis. $40 \%$ of individuals with the disorder experience significant difficulties with daily activities to the point of interfering with work-related or social roles ${ }^{8}$.

In Al-Modeer et al. ${ }^{9}$, arthritis ranked as the fourth $(29.5 \%)$ most prevalent diseases among elderly females. This might be due to the postmenopausal osteoporotic changes among females. A study by Moharana et al. ${ }^{10}$ found that, $37.0 \%$ of females were having osteoarthritis. The Vishnoi et al. ${ }^{11}$, found that, the prevalence of osteoarthritis was $12.6 \%$, more in females than males $(13.71 \%$ vs. $11.93 \%)$. Ubaidula et al. ${ }^{12}$ reported that, the prevalence of osteoarthritis was $28.0 \% .32 .6 \%$ in females and $24.2 \%$ in males.

In Arar city, Northern Saudi Arabia, up to our knowledge, no previous community based studies described the pattern of osteoarthritis of the knee joint was available.

This study was carried out aimed to determine the prevalence and determinant factors of osteoarthritis of the knee among elderly population in Arar, KSA 


\section{PARTICIPANTS AND METHODS}

The present cross sectional community based study was conducted in Arar city, the capital of Northern Borders Governorate on 238 adult people of age 60 years and more. The sample size was calculated using the sample size equation: $\mathrm{n}=\mathrm{z}^{2} \mathrm{p}(1-\mathrm{p}) / \mathrm{e}^{2}$, considering target population more than 1000 , and study power $95 \%$. Systematic random sampling technique was followed. After identifying the first house randomly in the selected area, every $9^{\text {th }}$ house was visited to include all the adult subjects residing in those selected houses till the required sample is covered.

Data was collected through personal interviews with the sampled population and filling a predesigned questionnaire which guided us to the data of socio-demographic characteristics such as age, sex, educational status and marital status, it also included smoking status and certain chronic diseases that may be prevalent among adults suggested to affect osteoporosis such as obesity, hypertension, diabetes millets and hyperlipidemia. The questionnaire included also questions regarding the already previously diagnosed osteoarthritis knee and its determinants, after ensuring the diagnosis by reviewing the accompanied health records and prescriptions and asking the accompanied caregivers about the case.

Ethical considerations: Data collector gave a brief introduction to the participants by explaining the aims and benefits of the study. Informed written consent was obtained from all participants. Anonymity and confidentiality of data were maintained throughout the study. There was no conflict of interest.

Statistical analysis: We utilized the statistical package for social sciences, version 16 (SPSS Inc., Chicago, Illinois, USA) to analyze the study data. The results were displayed as counts and percentages. The $\mathrm{X}^{2}$ test was used as a test of significance, and differences were considered significant at $P$ value less than 0.05 .

\section{RESULTS}

Table 1 illustrates the socio-demographic characteristics of the studied elderly population. The table showed that, mean age $( \pm$ SD) was 70.4 $( \pm 9.3)$ years, male to female ratio was 48.3 to 51.7 , illiteracy constitutes $47.1 \%$ and primary school literates were $18.9 \%$. As regards working, $15.3 \%$ were shepherd, $64.2 \%$ were not working and $20.5 \%$ were retired. Married were $60.9 \%$ while $34.0 \%$ were widow.

Figure 1 illustrates the percentage distribution of Osteoarthritis knee among the elderly population. The overall prevalence rate of Osteoarthritis knee found in this study was $24.5 \%$.

Table 2 illustrates the prevalence of Osteoarthritis knee and other related chronic diseases among the studied population. Hypertension was found in $44.5 \%$, myocardial infarction in $10.1 \%$, hypothyroidism in $12.2 \%$, diabetes $61.3 \%$, diabetic nephropathy in $5.5 \%$ and renal insufficiency in $7.1 \%$. As regards the BMI, about half $(43.7 \%)$ were obese, $27.7 \%$ overweight.

Table 3 illustrates the relationship between Osteoarthritis knee and age group, sex, DM, BMI group, thyroid disease and hypertension in the studied elderly population. Osteoarthritis was almost equal in females and males $(26.8 \%$ and $26.1 \%$, respectively), it was insignificantly associated with increasing age, female sex, hypertension, diabetes, $(\mathrm{P}>0.05)$ while significantly associated with BMI.

Table (1): Socio-demographic characteristics and smoking among the studied elderly, Arar, 2017 $(\mathrm{N}=238)$.

\begin{tabular}{|c|c|c|}
\hline Variables & $\begin{array}{c}\text { Frequency } \\
\text { (No.) }\end{array}$ & Percent $(\%)$ \\
\hline Age group & & \\
\hline $60-$ & 150 & 63.0 \\
\hline $70-$ & 65 & 27.3 \\
\hline $80+$ & 23 & 9.7 \\
\hline Mean age $( \pm$ SD) & & $70.4 \pm 9.3$ \\
\hline Sex & 123 & 51.7 \\
\hline Female & 115 & 48.3 \\
\hline Male & & \\
\hline Education & 112 & 47.1 \\
\hline Illiterate & 45 & 18.9 \\
\hline Primary & 22 & 9.2 \\
\hline Secondary & 41 & 17.2 \\
\hline University or more & 18 & 7.6 \\
\hline Preparatory & & 15.3 \\
\hline Working status & 35 & 64.2 \\
\hline Shepherd & 147 & 20.5 \\
\hline No work & 47 & \\
\hline Retired & 81 & 34.0 \\
\hline Marital status & 6 & 2.5 \\
\hline Widow & 60.9 \\
\hline Single & & \\
\hline Married & & \\
\hline Divorced & & \\
\hline
\end{tabular}




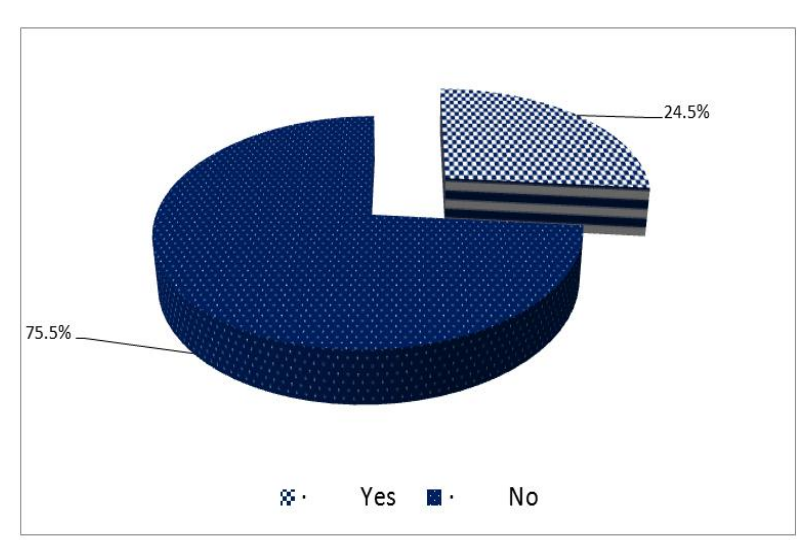

Figure (1): Prevalence of Osteoarthritis knee among elderly population in Arar city, Northern Saudi Arabia, 2017

Table (2): Prevalence of Osteoarthritis knee and other related chronic diseases among the studied elderly population, Arar, 2017 ( $\mathrm{N}=229)$.

\begin{tabular}{|l|c|c|}
\hline \multicolumn{1}{|c|}{ Osteoarthritis knee } & No. & \% \\
\hline Yes & 63 & 26.5 \\
\hline No & 175 & 73.5 \\
\hline Cardiovascular diseases & & \\
\hline Hypertension & 106 & 44.5 \\
\hline Ischemic heart diseases & 36 & 15.2 \\
\hline Previous myocardial infarction & 24 & 10.1 \\
\hline Thyroid diseases & & \\
\hline Hyperthyroidism & 12 & 5.0 \\
\hline Hypothyroidism & 29 & 12.2 \\
\hline Diabetes & & \\
\hline Yes & 146 & 61.3 \\
\hline No & 44 & 18.5 \\
\hline Renal problems & & \\
\hline Diabetic nephropathy & 13 & 5.5 \\
\hline Renal insufficiency & 17 & 7.1 \\
\hline Chronic renal failure & 2 & .8 \\
\hline Body Mass Index (kg/m2) status & & \\
\hline Underweight & 8 & 3.4 \\
\hline Normal & 60 & 25.2 \\
\hline Overweight & 66 & 27.7 \\
\hline Obese & 104 & 43.7 \\
\hline Mean BMI ( SD) & 163 & $30.0 \pm 10.2$ \\
\hline Smoking & & \\
\hline Non smoker & & \\
\hline Smokers & & \\
\hline Ex-Smoker & & \\
\hline & & \\
\hline
\end{tabular}

Table (3): The relationship between Osteoarthritis knee and age group, sex, DM, BMI group, Thyroid disease and Hypertension in the studied elderly population, Arar, 2017.

\begin{tabular}{|c|c|c|c|c|}
\hline \multirow[b]{2}{*}{ Variables } & \multicolumn{2}{|c|}{ Osteoarthritis knee } & \multirow{2}{*}{$\begin{array}{c}\text { Total } \\
(\mathbf{N}=229)\end{array}$} & \multirow[b]{2}{*}{$P$ value } \\
\hline & $\begin{array}{c}\text { Yes } \\
(\mathrm{N}=65)\end{array}$ & $\begin{array}{c}\text { No } \\
(\mathrm{N}=173) \\
\end{array}$ & & \\
\hline \multicolumn{5}{|l|}{ Age group } \\
\hline \multirow{2}{*}{$60-$} & 37 & 113 & 150 & \multirow{6}{*}{0.43} \\
\hline & $24.7 \%$ & $75.3 \%$ & $100.0 \%$ & \\
\hline \multirow{2}{*}{ 70- } & 21 & 44 & 65 & \\
\hline & $32.3 \%$ & $67.7 \%$ & $100.0 \%$ & \\
\hline \multirow{2}{*}{$80+$} & 5 & 18 & 23 & \\
\hline & $21.7 \%$ & $78.3 \%$ & $100.0 \%$ & \\
\hline \multicolumn{5}{|l|}{ Sex } \\
\hline \multirow{2}{*}{ Female } & 33 & 90 & 123 & \multirow{4}{*}{0.507} \\
\hline & $26.8 \%$ & $73.2 \%$ & $100.0 \%$ & \\
\hline \multirow{2}{*}{ Male } & 30 & 85 & 115 & \\
\hline & $26.1 \%$ & $73.9 \%$ & $100.0 \%$ & \\
\hline \multicolumn{5}{|c|}{ Diabetes Mellitus } \\
\hline \multirow{2}{*}{ Yes } & 34 & 112 & 146 & \multirow{4}{*}{0.234} \\
\hline & $23.3 \%$ & $76.7 \%$ & $100.0 \%$ & \\
\hline \multirow{2}{*}{ No } & 15 & 29 & 44 & \\
\hline & $34.1 \%$ & $65.9 \%$ & $100.0 \%$ & \\
\hline \multicolumn{5}{|l|}{ BMI group } \\
\hline \multirow{2}{*}{ Underweight } & 0 & 8 & 8 & \multirow{8}{*}{0.041} \\
\hline & $.0 \%$ & $100.0 \%$ & $100.0 \%$ & \\
\hline \multirow{2}{*}{ Normal } & 23 & 37 & 60 & \\
\hline & $38.3 \%$ & $61.7 \%$ & $100.0 \%$ & \\
\hline \multirow{2}{*}{ Overweight } & 14 & 52 & 66 & \\
\hline & $21.2 \%$ & $78.8 \%$ & $100.0 \%$ & \\
\hline \multirow{2}{*}{ Obese } & 26 & 78 & 104 & \\
\hline & $25.0 \%$ & $75.0 \%$ & $100.0 \%$ & \\
\hline \multicolumn{5}{|l|}{ Hypertension } \\
\hline \multirow{2}{*}{ Yes } & 31 & 99 & 130 & \multirow{4}{*}{0.195} \\
\hline & $23.8 \%$ & $76.2 \%$ & $100.0 \%$ & \\
\hline \multirow{2}{*}{ No } & 32 & 76 & 108 & \\
\hline & $29.6 \%$ & $70.4 \%$ & $100.0 \%$ & \\
\hline
\end{tabular}

\section{DISCUSSION}

Musculoskeletal complaints are common among elderly populations, having significant impact on functional ability. Osteoarthritis (OA) constitutes a major disease and disability burden worldwide, particularly in aging populations in developed regions, being the fifth largest contributor to disability life years. The commonest site of joint pain was the knees. Joint pain was associated with functional impairment, depressive symptoms, increased doctor consultations, and sleep problems ${ }^{13}$.

The present cross sectional community based study was conducted in Arar city, the capital of Northern Borders Governorate on 238 elderly people of age 60 years and more, aimed to determine the prevalence and determinant factors of osteoarthritis of the knee among elderly population in Arar, KSA 
The present study found osteoarthritis of the knee affected $24.5 \%$ of the studied elderly population. It was found in $26.8 \%$ of females and $26.1 \%$ of males. Al-Modeer et al ${ }^{9}$ which found the prevalence of osteoarthritis to be $29.5 \%$ which is supportive to our finding. Al-Arfaj et al. ${ }^{14}$ found the prevalence of reaching $30.8 \%$ in those aged $46-$ 55 years and $60.6 \%$ in the age group $66-75$ years. Sushma et al. ${ }^{15}$ reported osteoarthritis prevalence of $53.15 \%$, which is higher than our findings.

Taking the high percentage of obesity (45.7\%) into consideration, it might be a good cause of the relatively prevalent osteoarthritis in the studied population,

In our study osteoarthritis was almost equal in females and males $(26.8 \%$ and $26.1 \%$, respectively), Al-Arfaj et al. ${ }^{14}$ reported that, knee osteoarthritis was seen in $53.3 \%$ of males and in $60.9 \%$ of females and the association with female sex was significant. In Fayoum, Egypt, osteoarthritis constituted $42.2 \%$ with significantly more prevalence in females than males $(\mathrm{P}<0.05){ }^{16}$, this agreed with many other studies reported higher prevalence of osteoarthritis in elderly females ${ }^{[17,18]}$.

In the current study osteoarthritis knee was significantly associated with BMI, the associated risk of $\mathrm{OA}$ with rise in BMI was also found in Ismail et al. ${ }^{19}$ who reported strong association between obesity and knee osteoarthritis in eastern Saudi Arabia. In contrast, Al-Arfaj et al. ${ }^{14}$ found insignificant associated risk of osteoarthritis knee with incremental rise in BMI. The association of clinical OA with weight and BMI only came apparent when the BMI was broken into quintiles.

Abo el-Fetoh et al. ${ }^{20}$ found insignificant effect of BMI on the occurrence of knee osteoarthritis among the studied population $(\mathrm{P}>0.05)$.

In our study Osteoarthritis knee was insignificantly associated with hypertension $(\mathrm{P}>0.05)$. The correlation between $\mathrm{OA}$ and hypertension has been reported positively before. The association of hypertension with OA was weak ${ }^{21,22}$

In our study Osteoarthritis knee was insignificantly associated with diabetes $(\mathrm{P}>0.05)$. Earlier results on the association between diabetes and OA were inconsistent. Hart $\boldsymbol{e t} \boldsymbol{a l}^{23}$ showed an association of diabetes with radiological OA of the knee independent of overweight, while Frey et $_{\text {al }}{ }^{24}$ could not show any association between diabetes and clinical OA.

\section{CONCLUSION AND RECOMMENDATIONS}

Osteoarthritis of the knee joint is common among elderly population in Arar, KSA. It was almost equal in females and males. So we recommend that, policy makers must condense their efforts to increase the awareness campaigns to protect and treat those vulnerable groups from this disease and its subsequent morbidities..

\section{REFERENCES}

1. Picavet H, Hazes J (2003): Prevalence of self reported musculoskeletal diseases is high. Ann Rheum Dis., 62:644-650

2. Elders MJ (2000): The increasing impact of arthritis on public health. J Rheumatol., 60: 68.

3. Multani N, Ouslander J, Verma S (2007): Principles of geriatric physiotherapy. New Delhi: Jaypee brothers medical publishers $j$

4. Mohamed NA(2013): The Relation between Environmental Factors and Health Related Mobility Disability of Elderly Women with Osteoarthritis in Southern Egypt. J Am Sci., 9(5):408-416

5. Sowers $M$, Lanchance $L$, Hochberg $M$ et al. (2000): Radiographically define osteoarthritis of the hand and knee in a young and middle aged African American and Caucasian women. Osteoarthritis Cartilage, 8: 69-77.

6. Heikkinen E (2006): Disability and physical activity in late life-research models and approaches. Eur. Rev. Aging.Phys. Act., 3: 3.

7. Halter J, Ouslander J, Tinetti $M$ et al. (2009): Hazzard Geriatric Medicine and Gerontology. 6thed. New York:The McGrawHill companies.

8. Stevermer C (2005): Functional movement assessment for individuals with knee osteoarthritis. Published thesis, DSN, Iowa: Iowa State University, Faculty of the Graduate, Available at http://www. proquest.com.

9. Al-Modeer A, Noha S. Hassanien et al. (2013): Profile of morbidity among elderly at home health care service in Southern Saudi Arabia. J Family Community Med., 20(1): 5357. 
10. Moharana P, Sahani N, Sahu T (2008): Health status of geriatric population attending the preventive geriatrics clinic of a tertiary health facility. J Community Med.,4:22-26.

11. Vishnoi B, Solanki S, Singhal G et al. (2015): Morbidity Profile of Elderly in Urban Slum of Udaipur, Rajasthan. Int J Oral Health Med Res., 2(1):9-12.

12. Ubaidula M, Inamdar I, Aswar $\mathrm{N}$ et al. (2014): Medical and psychosocial profile of geriatric population. IOSR-JDMS., 13(3): 2933.

13. Woo J, Lau E, Lau C et al. (2003): Socioeconomic impact of osteoarthritis in Hong Kong: Utilization of health and social services, and direct and indirect costs. Arthritis care and research, 49(4): 526-534

14. Al-Arfaj A, Al-Boukai A (2002): Prevalence of radiographic knee osteoarthritis in Saudi Arabia. Clin Rheumatol., 21(2):142-5.

15. Sushma Tiwari, Ashutosh $K$ et al. (2011): Prevalence of health problems among elderly A study in rural population in Varanasi. Indian Journal of preventive and social medicine, 41(3):226-230.

16. Hassan SK (2015): A study of morbidity pattern among geriatric population in Fayoum Governorate, Egypt. Journal of American Science, 11:90-95.

17. AL-Doghether M, AL-Megbil $T$ (2004): Determinants of prescribing for the elderly in primary health care. Middle East Journal of Family Medicine, 2(1):1-5.

18. Jain N, Pawar A, Ravjibhai H et al. (2010): Morbidity profile of elderly people in slums of surat city. Natl J Community Med.,1:52-4.

19. Ismail A, Abdulwahab A, Almulhim A (2006): Osteoarthritis and obesity in Eastern Saudi Arabia. Saudi Medical Journal, 27(11):1742-1744

20. Abo el-Fetoh NM, Alanazi AM, Alotaibi HK et al. (2017): Musculoskeletal diseases in elderly population of Arar city, kingdom of saudi Arabia: a cross-sectional study. European Journal of Research in Medical Sciences, 5(1):35-42.

21. Davis MA, Ettinger WH, Neuhaus JM (1988): The role of metabolic factors and blood pressure in the association of obesity with ostearthritis of the knee. J Rheumatol., 15:1827-1832.
22. Lawrence JS (1975): Hypertension in relation to musculoskeletal disorders. Ann Rheum Dis., 34: 451-456.

23. Hart D J, Doyle D V, Spector T D (1995): Association between metabolic factors and knee osteoarthritis in women: the Chingford Study. J Rheumatol., 221118-221123.

24. Frey M I, Barrett-Connor E, Sledge $P$ A et al. (1996): The effect of noninsulin dependent diabetes mellitus on the prevalence of clinical osteoarthritis. A population based study. J Rheumatol., 23716-722. 